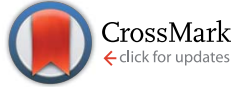

Cite this: RSC Adv., 2015, 5, 48551

Received 18th March 2015 Accepted 12th May 2015

DOI: $10.1039 / \mathrm{c} 5 \mathrm{ra04804d}$

www.rsc.org/advances

\section{Identification of the first surrogate agonists for the G protein-coupled receptor GPR132 $\dagger$}

\author{
Mohamed A. Shehata, $\ddagger^{\mathrm{a}}$ Hanna Belcik Christensen, $\ddagger^{\mathrm{a}}$ Vignir Isberg, ${ }^{\text {ab }}$ Daniel Sejer \\ Pedersen, ${ }^{a}$ Andreas Bender, ${ }^{\text {b }}$ Hans Bräuner-Osborne ${ }^{\star a}$ and David E. Gloriam $\S^{\star a}$
}

GPR132 is an orphan class A G protein-coupled receptor. It has been proposed to be activated by protons and to regulate apoptosis, atherosclerosis and inflammation, but these results are still preliminary. In the current work, we designed and screened a focused compound library using a $\beta$-arrestin recruitment assay, and thereby identified the first disclosed surrogate GPR132 agonist 1 with a potency of $3.4 \mu \mathrm{M}$. This constitutes the first available pharmacological tool for the in vitro characterization of the orphan receptor GPR132. The testing of 32 analogs furthermore identified a number of compounds with lower activity - of which six were agonists and two were antagonists - that were used to construct preliminary structure-activity relationships. Docking followed by a molecular dynamics simulation of compound 1 in a structural model of GPR132 displayed the putative interactions for the key ligand functionalities.

\section{Introduction}

G protein-coupled receptors (GPCRs) constitute the largest family of cell surface receptor proteins. ${ }^{1}$ They are involved in the regulation of a wide range of physiological processes including vision, metabolism, neurotransmission and inflammation, ${ }^{2,3}$ and approximately $30 \%$ of FDA-approved drugs are thought to target GPCRs. ${ }^{4,5}$ More than 800 different sequences in the human genome encode for GPCRs, of which approximately 350 sequences encode for non-olfactory receptors. ${ }^{6}$ Their involvement in various physiological processes has made GPCRs one of the most pursued target classes in academia as well as industry. GPR132 has been ascribed several putative endogenous ligands. In 2001, lysophosphatidylcholine was proposed ${ }^{7}$ to be the natural agonist but these results were later retracted, ${ }^{8}$ and in 2004 it was shown to function as an antagonist. ${ }^{9}$ In 2005 , another lipid derivative, 9-hydroxy-10E, 12Z-octadecadienoic acid, was presented as an alternative endogenous agonist, ${ }^{10}$ but this could not be confirmed in another study ${ }^{11}$ Independent analyses have instead provided evidence that GPR132 functions as a sensor for extracellular $\mathrm{pH}^{9,12}$ This is in agreement with a phylogenetic analysis that grouped GPR132 with the proton-sensing receptors GPR4, GPR65, and GPR68. ${ }^{13}$

\footnotetext{
${ }^{a}$ Department of Drug Design and Pharmacology, Faculty of Health and Medical Sciences, University of Copenhagen, Jagtvej 162, 2100 Copenhagen, Denmark. E-mail: gloriam@sund.ku.dk; hbo@sund.ku.dk; Tel: +45353361 62; +45 39179659 ${ }^{b}$ Centre for Molecular Informatics, Department of Chemistry, University of Cambridge, Lensfield Road, Cambridge CB2 1EW, UK

$\dagger$ Electronic supplementary information (ESI) available. See DOI: $10.1039 / \mathrm{c} 5 \mathrm{ra} 04804 \mathrm{~d}$

\$ These authors contributed equally.

$\S$ These authors contributed equally.
}

Surrogate GPR132 ligands were reported by Invitrogen Discovery Sciences and Amgen in 2009, but without disclosing their structures. ${ }^{11}$ The physiological function of GPR132 is still unknown, although several hypotheses have been presented. Firstly, studies in this direction found that GPR132 triggers chemotaxis of monocytic phagolytic cells towards apoptotic cell remnants $^{14}$ and promote anti-inflammatory responses in human skin epidermal cells and keratocytes by suppressing DNA synthesis and freezing specific cell cycle phases. ${ }^{15}$ Secondly, GPR132 is expressed on macrophages, ${ }^{16}$ and has been suggested to be involved in atherosclerotic lesion growth in the aortic tissue and the coronaries. ${ }^{17}$ However, later studies display ambiguous results as the formation of atherosclerosis lesions was suppressed and promoted by knockout and silencing of the GPR132 gene, respectively. ${ }^{18,19}$ Finally, over-expression of GPR132 has been found to inhibit tyrosine kinases involved in the activation of $\mathrm{BCR} / \mathrm{ABL}$ fusion proteins, ${ }^{20}$ which play a key role in the oncogenesis and proliferation of some cancers. ${ }^{21}$

In this article, we now disclose the first surrogate agonist for GPR132 with potency in the single micro-molar range (Fig. 1, Chart 1). Receptor structure modeling and ligand docking studies present the putative molecular mechanism of action, which could contribute to future structure-based optimization towards in vivo application. The description of the first publically available GPR132 surrogate agonist is an important first step towards the pharmacological and physiological characterization of the receptor.

\section{Materials and methods}

\section{GPCR-focused compound libraries}

We designed focused GPCR screening libraries based on identification of novel privileged structures, which are core scaffolds 
A

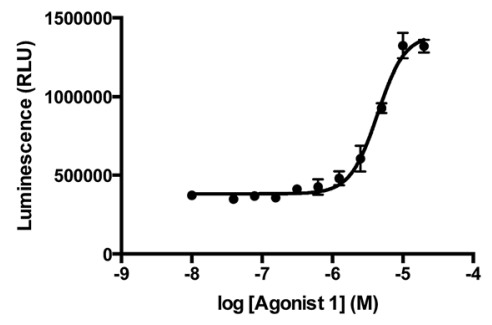

B

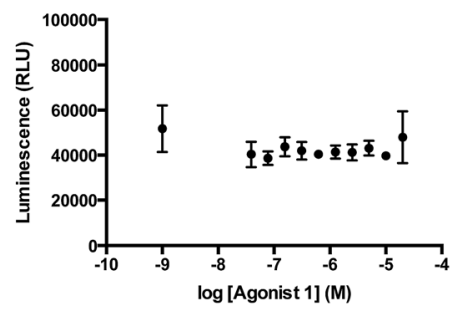

C

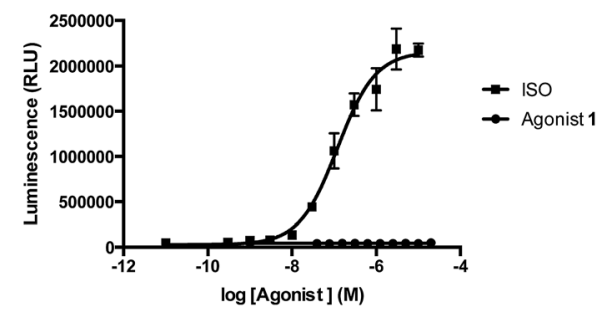

Fig. 1 Pharmacological characterization of the identified GPR132 agonist 1. (A) Representative concentration-response curve of agonist 1 on the human GPR132 receptor. The calculated $\mathrm{pEC}_{50}$ value for 1 is $5.46 \pm 0.09$ ( $\left.E C_{50}=3.4 \mu \mathrm{M}\right)$. Counter screening of 1 ( $\mathrm{B}$ and $\mathrm{C}$ ) and the concentration-response curve of ISO on the $\beta_{2}$-adrenergic receptor (C). ISO is a $\beta_{2}$-adrenergic receptor agonist and has been used as a positive control in the assay. The calculated $\mathrm{pEC} 50$ value for ISO equals $6.97 \pm 0.05$. Measurements of luminescence (RLU) in response to receptors activation have been performed in PathHunter $\beta$-arrestin recruitment assays, in $\mathrm{CHO}$ cell lines expressing human GPR132 (A) or $\beta_{2}$-adrenergic receptor (B and $C$ ). All data represent mean \pm SD from one representative out of five (A) or two (B and $C$ ) independent experiments performed in triplicates.

with known activity at multiple diverse receptor targets. ${ }^{22-24} \mathrm{We}$ fetched all $\sim 62000$ GPCR-active ligands from ChEMBL ver.14 ${ }^{25}$ and identified $\sim 50$ frequent substructures using Gaston $^{26}$ that form parts of existing ligands for several diverse GPCR targets, e.g. small molecule, peptide and lipid receptors. The design of focused screening libraries started by querying these "privileged structures" against the entire Enamine screening compound collection in Instant JChem. ${ }^{27}$ More than 50000 compounds were exported to Schrödinger Maestro, ${ }^{28}$ prepared with LigPrep $^{29}$ and physicochemical properties were calculated with QikProp. ${ }^{9}$ Filters were applied to remove reactive structural groups and to enrich the dataset for compounds with desirable solubility, size and interaction features. Specifically the applied filters were: molecular weight (3-500), rotatable bonds (2-10), hydrogen bond donors and acceptors $(0-5$ and $0-10$, respectively, but requiring at least one of either), $Q \log S(>-6), Q \log P$ $(<5)$, FISA $(7-330)$ and number of rings $(\max 5)$. The remaining compounds were clustered with the Maestro script for Canvas similarity and clustering and 1-3 representative compounds were handpicked from each cluster. The final library consisted of $\sim 1600$ lead- and drug-like screening compounds specifically selected for likely GPCR-activity.

To allow for library sub-selection based on target binding site charge, the overall library was divided into 3 sub-libraries containing negatively, neutral and positively charged compounds, respectively. All compounds were purchased from Enamine (Kiev, Ukraine) as $10 \mu \mathrm{L}$ of $10 \mathrm{mM}$ solution in $100 \%$ frozen DMSO plated on 384 well plates. The structure of compound 1 was confirmed by ${ }^{1} \mathrm{H}$ NMR and HPLC-MS (Chart SI $2 \dagger$ ).

\section{Pharmacological assaying}

The G protein signaling pathways of many orphan GPCRs are still unknown, making second messenger-based assays unsuitable for screening for orphan receptor ligands. Thus, the $\beta$ arrestin2 recruitment assay (DiscoveRx) ${ }^{30}$ was employed in the screening and the subsequent hit validation. Since recruitment of $\beta$-arrestins constitutes an universal "off-switch" for GPCRs, assays based on $\beta$-arrestins binding to the activated receptors should offer the possibility of detecting GPCRs activation regardless of the routes of $\mathrm{G}$ protein signaling. DiscoveRx $\beta$ arrestin recruitment assays have been used previously for identification of endogenous and surrogate ligands of orphan GPCRs. ${ }^{31,32}$

24 hours before performing the assay, the PathHunter eXpress GPR132 or $\beta_{2}$-adrenergic receptor (ADRB2) cells were thawed in $9.5 \mathrm{~mL}$ of cell plating reagent 1 or 0 , respectively. Subsequently, $20 \mu \mathrm{L}$ of cell suspension/well was seeded in a 384well plate (Greiner Bio-One) and incubated overnight at $37^{\circ} \mathrm{C}$ and $5 \% \mathrm{CO}_{2}$. On the day of assaying, the compound libraries were thawed on a plate shaker at $450 \mathrm{rpm}$ and ligand plates where prepared with $100 \mu \mathrm{M}$ compound solution in ligand buffer (Hank's balanced salt solution, 10 mM HEPES, pH 7.4). Subsequently, $5 \mu \mathrm{L}$ of the ligand solution was added to each well of the cell-containing plate. Plates were sealed and incubated for $90 \mathrm{~min}$ at $37^{\circ} \mathrm{C}$, followed by $30 \mathrm{~min}$ incubation at RT. For antagonist mode screening, cells were pre-incubated for $30 \mathrm{~min}$ at $37{ }^{\circ} \mathrm{C}$ with the $\mathrm{EC}_{80}$ of $\mathbf{1}(8.5 \mu \mathrm{M}),{ }^{33}$ followed by $60 \mathrm{~min}$ incubation at $37^{\circ} \mathrm{C}$ with the tested compound. Thereafter, 12.5 $\mu \mathrm{L}$ of PathHunter detection solution (DiscoveRx) was added to each well and plates were incubated in darkness for $60 \mathrm{~min}$. Chemiluminescence, indicated as relative luminescence units, was measured with an EnSpire 2300 Multilabel Reader (PerkinElmer, Waltham, MA, USA).

Compounds were screened at $20 \mu \mathrm{M}$, in single measurements, with $1 \%(\mathrm{v} / \mathrm{v})$ final concentration of DMSO. Hits (compounds with the activity greater than three times standard deviations of the assay buffer) were subsequently retested in concentration-response studies. Analogs of 1 were tested in both agonist and antagonist mode (in the presence of $8.5 \mu \mathrm{M}$ of 1 ) and a cut-off of $5 \%$ and $25 \%$, respectively, was applied to distinguish active compounds in the agonist and antagonist screen mode, respectively. The $\mathrm{EC}_{80}$ of agonist for the antagonist mode screening was chosen as a compromise between a large assay window (to maximize signal to noise ratio) and sensitivity to antagonist, ${ }^{33}$ based on the assumption that the tested compounds would behave as competitive antagonists given their structural similarity with compound 1. To increase chances of observing competitive antagonism, the ligands were tested in their highest soluble concentration $(20 \mu \mathrm{M})$.

Curve fitting was performed by non-linear regression using the sigmoidal dose-response equation (variable slope) in 
GraphPad Prism 6.0 (GraphPad Software, San Diego, C.A, USA).

\section{GPR132 homology modeling}

The crystal structure ${ }^{34}$ of the inactive human protease-activated 1 receptor (PAR1; PDB: 3VW7) was selected as the main template, using the GPCRdb template selection tool. ${ }^{35}$ The resolution of the PAR1 structure is $2.20 \AA$. The protein sequence similarity between the target and template receptor is $64 \%$ in the seven trans-membrane helical (7 TM) region. Based on sequence length and similarity, a second template, the human chemokine receptor 4 (CXCR4) structure (PDB: 3ODU), ${ }^{36}$ was used for the part from the second extracellular loop (ECL2) spanning between TM5 and the cysteine forming the conserved disulfide bridge to TM3. To improve the GPR132 structure model for subsequent ligand docking, non-conserved amino acids within the binding pocket had their rotamers defined based on an in-house GPCR position-specific rotamer library that contains rotamers extracted from all published GPCR crystal structures. ${ }^{37}$ In this manner, the rotamers could be finetuned for $\mathrm{S}^{1 \times 31}, \mathrm{~L}^{1 \times 35}, \mathrm{Y}^{1 \times 39}, \mathrm{~W}^{2 \times 60}, \mathrm{I}^{2 \times 64}, \mathrm{~T}^{3 \times 28}, \mathrm{Y}^{5 \times 40}, \mathrm{~F}^{5 \times 43}, \mathrm{Y}^{6 \times 51}$, $\mathrm{H}^{6 \times 52}, \mathrm{~V}^{6 \times 54}, \mathrm{~K}^{6 \times 58}, \mathrm{~L}^{7 \times 30}, \mathrm{~L}^{7 \times 38}$, and $\mathrm{T}^{7 \times 42}$. The protein sequences of the chimeric template and target were aligned with MEGA5.2, ${ }^{38}$ using the GPCRdb alignments as a reference for the seven helices.

Modeller9v13 (ref. 39) was applied to build 500 homology models and the best model was selected based on DOPE score. The model backbone was assessed by Ramachandran ${ }^{40}$ plots (Fig. SI1†) within the PROCHECK ${ }^{41}$ webserver. The GPR132 model was prepared with the Schrödinger Protein Preparation Wizard, ${ }^{42}$ including an hydrogen optimization at $\mathrm{pH} 7$ of the ionizable polar groups using Maestro PROPKA. ${ }^{42}$

\section{Ligand docking and molecular visualization}

Compound $\mathbf{1}$ was docked with Glide ${ }^{\mathbf{4 3}}$ in the extra precision mode, and flexible ligand sampling was applied. The partial charges of the ligands were assigned by Epik ${ }^{\mathbf{4}}$ using the OPLS_2005 force field. The van der Waals radii scaling factor was set to 0.8 and the partial charge cutoff to 0.15. Further options were set to allow the rotation of hydroxyl hydrogen atoms in the binding site, enhance the planarity of conjugated $\pi$-systems, and to include the Epik state penalties to the scoring calculations. Subsequently, QM-Polarized Ligand Docking ${ }^{45}$ (QPLD) was applied. Jaguar ${ }^{\mathbf{4 6}}$ performed the partial charge calculations with the QM estimation level set to accurate (6$31 \mathrm{G}^{*} / \mathrm{LACVP} *$ basis set, B3LYP density functional, and "Ultrafine" self-consistent field accuracy level). SiteMap ${ }^{47}$ was used to map the GPR132 binding cavity. Residue positions were indexed with the GPCRdb scheme, ${ }^{48}$ which corrects for helical bulges and constrictions. 2D structures were drawn in MarvinSketch ${ }^{\mathbf{4 9}}$ and 3D structures were visualized using PyMOL. ${ }^{50}$

\section{Molecular dynamics simulation}

The receptor-ligand complex was minimized using the energy minimization tool in MacroModel $^{51}$ Schrödinger. The TNCG (Truncated Newton Conjugate Gradient) minimization method was used with maximum iteration steps set to 5000, and the convergence gradient to 0.001 . Desmond ${ }^{52}$ was employed to conduct a molecular dynamics (MD) simulation for $20 \mathrm{~ns}$ on the complex in the predefined POPC membrane model. Explicit water molecules were handled using the simple point charge model. Constant temperature and pressure were applied at 300 $\mathrm{K}$ and 1.01325 bar, respectively. The system was coupled to an isotropic Berendsen thermo- and barostat, with relaxation set to 1 and 2 ps respectively.

\section{Results and discussion}

\section{Identification of the first surrogate GPR132 agonist}

Screening of the GPCR-focused libraries against the human GPR132 receptor yielded a hit $(\mathbf{1}$, Chart 1$)$ with $3.4 \mu \mathrm{M}$ potency (Fig. 1A). Compound 1 is racemic and thus one of the enantiomers may have a higher potency than observed for the racemate. To evaluate whether the observed increase in luminescence is GPR132-mediated, 1 was also tested at another class A GPCR, the $\beta_{2}$-adrenergic receptor. Ligand 1 did not induce $\beta$-arrestin recruitment in $\mathrm{CHO}$ cells expressing $\beta_{2}$-adrenergic receptor, while the positive control isoproterenol (ISO) produced a concentration-dependent response with an $\mathrm{EC}_{50}$ of approximately $100 \mathrm{nM}$ (Fig. 1B and C). Hence, we concluded that the activity of $\mathbf{1}$ is not unspecific, but mediated via GPR132.

\section{GPR132 structure model and compound 1 binding mode}

To achieve a GPR132 model of sufficient quality for ligand docking, we found that it was necessary to locally replace the main template (the protease-activated 1 receptor) with alternative templates. The part of the second extracellular loop (ECL2) from the conserved cysteine $\left(\mathrm{C}^{45 \times 50}\right)$ to TM5 is crucial as it acts as a lid of the binding pocket in many class A GPCRs, and it often forms ligand interactions. ${ }^{53}$ This segment was longer in the protease-activated 1 receptor (10 instead of 7 residues); thus the human chemokine receptor 4 (also has 7 residues) was the most suitable template for modeling this segment. Furthermore, for binding pocket residues not conserved between the protease-activated 1 receptor and GPR132, we applied rotamers from the other most homologous receptors. In this way, 29 out of $36(\sim 81 \%)$ side chains within the GPR132 binding cavity could be defined according to a conserved crystal structure template. Validation of the GPR132 model in PROCHECK ${ }^{\mathbf{1 1}}$ showed that $93.5 \%$ of the residues are within the optimal backbone torsion angles and $6.5 \%$ are near-optimal (Fig. SI $1 \dagger$ ).

The docking pose of ligand 1 displayed close shape complementarity with the GPR132 binding pocket and good agreement with the receptor hydrophobic and hydrogen bonding sites (Fig. SI2A-C $\dagger$ ). The $R$ - and $S$-enantiomers exhibited very similar binding mode. However, the hydrophobic binding site matched the methyl substituent better for the $R$ enantiomer, which was therefore chosen for the further analyses. Five residues displayed hydrogen bond interactions with the ligand namely $\mathrm{Y}^{1 \times 39}, \mathrm{D}^{45 \times 52}, \mathrm{H}^{4 \times 57}, \mathrm{Y}^{6 \times 51}$, and $\mathrm{K}^{6 \times 58}$. Both Glide and QPLD resulted in identical outcome. To evaluate the 


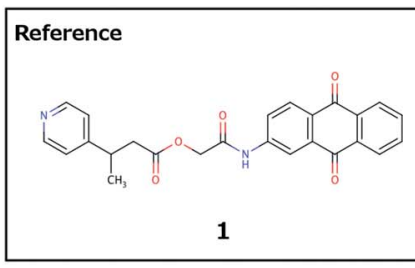

$\underbrace{}_{0}$<smiles>COc1ccccc1NCCC(=O)OCC(=O)Nc1ccc2c(c1)C(=O)c1ccccc1C2=O</smiles>

$9^{\mathrm{Ag}}$<smiles>O=C(COC(=O)CC1CCCC1)Nc1cc2c(cc1Cl)C(=O)c1ccccc1C2=O</smiles>

13<smiles>O=C(COC(=O)c1ccc(O)cc1)Nc1ccc2c(c1)C(=O)c1ccccc1C2=O</smiles>

17<smiles>N#Cc1ccc(C(=O)OCC(=O)Nc2ccc3c(c2)C(=O)c2ccccc2C3=O)cc1</smiles>

21

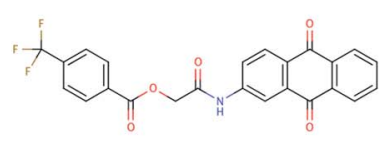

25

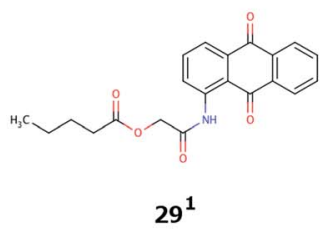

$\overbrace{0}$

$33^{\mathrm{Ag}}$
Same length linker<smiles></smiles><smiles>O=C(COC(=O)COc1ccccc1)Nc1ccc2c(c1)C(=O)c1ccccc1C2=O</smiles>

3<smiles>O=C(COC(=O)CNC(=O)c1ccccc1)Nc1ccc2c(c1)C(=O)c1ccccc1C2=O</smiles>

6<smiles>COc1ccc(OCCC(=O)OCC(=O)Nc2ccc3c(c2)C(=O)c2ccccc2C3=O)cc1</smiles><smiles>O=C(COC(=O)CCCc1c[nH]c2ccccc12)Nc1ccc2c(c1)C(=O)c1ccccc1C2=O</smiles>

$11^{\text {Ant }}$

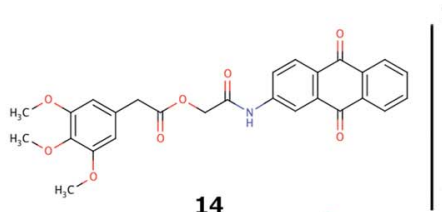

14<smiles>O=C(COC(=O)C1CC2C=CC1C2)Nc1ccc2c(c1)C(=O)c1ccccc1C2=O</smiles>

$18^{\mathrm{Ag}}$

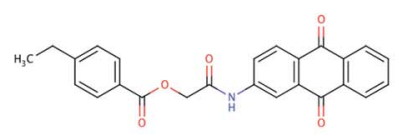

22

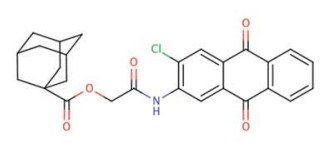

26

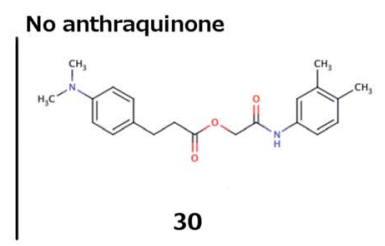

Linker 2 atoms shorter<smiles>O=C(COC(=O)c1ccccc1)Nc1ccc2c(c1)C(=O)c1ccccc1C2=O</smiles><smiles></smiles>

19<smiles>Nc1cc(N)cc(C(=O)OCC(=O)Nc2ccc3c(c2)C(=O)c2ccccc2C3=O)c1</smiles>

23<smiles>CCC(=O)OCC(=O)Nc1ccc2c(c1)C(=O)c1ccccc1C2=O</smiles>

27

No anthraquinone

Terminal 1,1-diphenyl

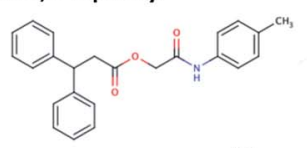

$31^{\mathrm{Ag}}$<smiles>O=C(COC(=O)CCc1ccccc1)Nc1cc2c(cc1Cl)C(=O)c1ccccc1C2=O</smiles>

4<smiles>O=C(COC(=O)CCC(=O)c1ccc(F)cc1)Nc1ccc2c(c1)C(=O)c1ccccc1C2=O</smiles>

Linker 1 atom shorter<smiles>[Z12]C(=O)Nc1cccc2c1C(=O)c1ccccc1C2=O</smiles><smiles>O=C(COC(=O)c1ccncc1)Nc1cccc2c1C(=O)c1ccccc1C2=O</smiles>

20

(1)

24

28

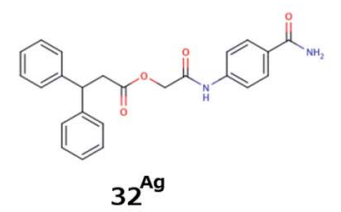

Chart 1 Chemical structures of the first disclosed GPR132 surrogate agonist 1 and its analogs $2-33 .{ }^{A g}$ denotes the six analogs 2, 9, 18, 31, 32, and 33 with weak agonistic activity. Ant denotes the two analogs 11 and 12 with weak antagonistic activity. ${ }^{1}$ marks the three 1 -substituted anthraquinone analogs 12,16 , and 29. 2D structures were drawn in MarvinSketch. ${ }^{49}$

accuracy of our docking procedure, we re-docked the ligands in the three most homologous GPCR crystal structures; the protease-activated 1 receptor (PDB: $3 \mathrm{VW} 7$ ), ${ }^{34}$ the $\mu$-opioid receptor (PDB: 4DKL) ${ }^{54}$ and the chemokine receptor type 5 (PDB: 4MBS) ${ }^{55}$ respectively. The docked ligands showed very similar poses as the crystallized with RMSD values of 0.643 , 1.306, and $0.270 \AA$ A, respectively (Fig. SI3A-C $\dagger$ ).

In our molecular dynamics simulation of the $\mathbf{1}$ - GPR132 complex, in a membrane and solvent environment, the ligand remained in the same binding cavity throughout the entire 20 
ns simulation (Video SI1 $\dagger$ ), confirming that the complex is stable. The observed interactions and their durations are summarized in Fig. 2. The anthraquinone of $\mathbf{1}$ appeared to be occupying a hydrophobic site between TM3-5 that provided $\pi-\pi$ aromatic (residues $\mathrm{F}^{3 \times 33}$ and $\mathrm{Y}^{5 \times 39}$ ) and hydrophobic (residues $\mathrm{I}^{5 \times 35}$ and $\mathrm{P}^{4 \times 59}$ ) contacts (Fig. 2C). The pyridinyl ring formed a $\pi-\pi$ interaction with $\mathrm{W}^{2 \times 60}$ and, together with the methylated linker; favorable hydrophobic contacts with several aliphatic residues could be seen (Fig. 2C).

The linker amide group displayed hydrogen bonding to both $\mathrm{Y}^{6 \times 51}$ and a bridging water molecule to $\mathrm{D}^{45 \times 52}$, a residue position in the second extracellular loop that often forms contact with class A receptor ligands. ${ }^{53}$ In shorter periods of the simulation, the bond with $\mathrm{Y}^{6 \times 51}$ was also indirectly formed via a water molecule (Fig. 2). All active analogs have this amide, indicating that its interactions could contribute to the stabilization of an active receptor conformation. The carbonyl oxygen in the amide linker also displayed a potential indirect interaction to $\mathrm{Y}^{5 \times 40}$ (Fig. 2C). On the other hand, the carbonyl oxygen in the propionate group presented indirect hydrogen bonding to $\mathrm{Y}^{6 \times 51}$ (Fig. 2C).

The oxygen atom in the 10-position of the anthraquinone ring displayed three putative water-mediated hydrogen bond interactions bridging $\mathrm{K}^{6 \times 58}, \mathrm{D}^{5 \times 32}$, and the backbone of $\mathrm{L}^{45 \times 54}$, respectively. The atom also presented a potential direct interaction with $\mathrm{Y}^{5 \times 40}$. The simulation showed that the most frequent hydrogen bonds were the indirect ones to $\mathrm{L}^{45 \times 54}$ and $\mathrm{D}^{5 \times 32}$ via bridging water molecules (Fig. $2 \mathrm{C}$ ). The oxygen in the 9-position presented a direct hydrogen bond interaction with $\mathrm{H}^{4 \times 57}$ or an indirect one with $\mathrm{D}^{45 \times 52}$ (Fig. 2C). The pyridinyl ring nitrogen interacted firmly with $\mathrm{Y}^{1 \times 39}$ (Fig. 2). Altogether, six of the seven polar ligand atoms displayed hydrogen bond interactions, whereof four mainly indirectly via water molecules, and two directly to the receptor side chains.

\section{Preliminary structure-activity relationships of compound 1 analogs}

The structures of compound $\mathbf{1}$ and the 32 tested analogs are shown in Chart 1. All active analogs have lower potency than $\mathbf{1}$, and because of their limited solubility, it was not possible to produce full concentration-response curves and derive $\mathrm{EC}_{50} / \mathrm{IC}_{50}$ values. Instead, their relatively weak activities are reported in Table 1 at their maximum soluble concentration, which was $10 \mu \mathrm{M}$ or $20 \mu \mathrm{M}$, respectively. Six of the analogs, namely 2, 9, 18, 31, 32 and 33, display weak agonistic activity

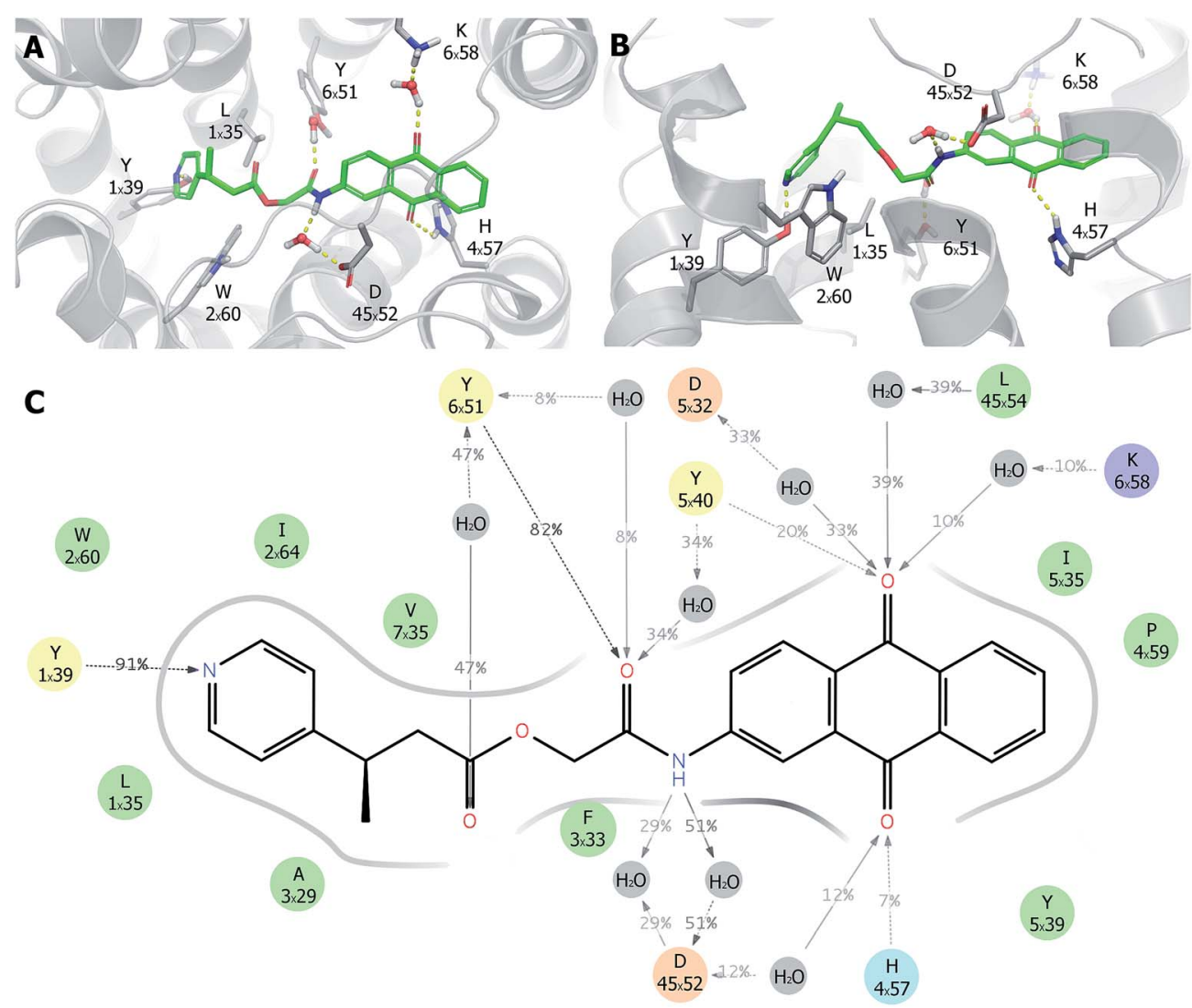

Fig. 2 (A) Top and (B) side views of a representative binding pose of compound 1 (green), obtained from the molecular dynamics simulation. Hydrogen bonds are shown in dashed yellow lines representing the pairings between the ligand polar groups and the different receptor residues (grey). The simulation ligand interactions diagram (C) represents a summary of the interactions observed in the simulation obtained from Desmond. All detected hydrogen bonds (grey lines) are represented with their corresponding percentages. Residue positions are indexed with the GPCRdb scheme ${ }^{48}$ to correct for bulges and constrictions. 
Table 1 Maximal effects ${ }^{a}$ of the active analogs $s^{b}$ of 1 at PathHunter eXpress $\mathrm{CHO}-\mathrm{K} 1$ cells expressing GPR132

\begin{tabular}{lrlll}
\hline Compound & Rel. $E_{\max }(\%)$ & SEM & Conc. $(\mu \mathrm{M})$ & $N$ \\
\hline $\mathbf{1}$ & 100 & - & - & 5 \\
$\mathbf{2}$ & 18 & 2.9 & 10 & 3 \\
$\mathbf{9}$ & 9 & 0.1 & 20 & 2 \\
$\mathbf{1 8}$ & 14 & 2.8 & 10 & 3 \\
$\mathbf{3 1}$ & 13 & 1.0 & 20 & 3 \\
$\mathbf{3 2}$ & 13 & 0.2 & 20 & 3 \\
$\mathbf{3 3}$ & 8 & 0.3 & 20 & 3
\end{tabular}

${ }^{a}$ The relative $E_{\max }$ of tested compounds was calculated by dividing the span of compound response by the span of 1 response in the same experiment and on the same plate. ${ }^{b}$ Compounds with a relative $E_{\max }$ higher than $5 \%$ were considered as agonists.

with relative $E_{\max }$ between 8 and $18 \%$ at the highest soluble concentration (10 or $20 \mu \mathrm{M}$, Table 1 ).

Compound 2 is the most similar analog to $\mathbf{1}$ and also has the highest activity of the analogs (relative $E_{\max }$ of $18 \%$ at $10 \mu \mathrm{M}$ ). It differs by having a terminal pyrimidine on a trigonal nitrogen instead of a pyridine on a tetrahedral carbon, which is also the chiral center in compound $\mathbf{1}$. Glide docking of compound 2 showed that the hydrogen bond to $\mathrm{Y}^{1 \times 39}$ is lost as this compound lacks the pyridine nitrogen in the 4-position (Fig. SI4A $\dagger$ ). Compounds 3-5 have a terminal phenyl moiety and in turn lack the methyl group, indicating that either a hydrogen bond acceptor in the aryl 4-position or a methyl function could be beneficial for activity. Compounds $\mathbf{9}$ and $\mathbf{1 0}$ contain a terminal meta- and para-methoxy-phenyl, respectively, on a linker that is extended by an extra nitrogen or oxygen atom, respectively, compared to $\mathbf{1}$. In our docking, the nitrogen in $\mathbf{9}$ formed a hydrogen bond to the backbone carbonyl of $\mathrm{C}^{45 \times 50}$ (forms a disulfide bridge from the second extracellular loop to the top of TM3), whereas the oxygen in 10 displayed no interaction (Fig. SI4B and $\mathrm{C} \dagger$ ). This provides a hypothesis for the activity of $\mathbf{9}$, as opposed to $\mathbf{1 0}$. In the final analogs with agonistic activity, 31-33, the 1,1-diphenyl group docked into the same site as the pyridine moiety, not the anthraquinone core, of compound 1 (Fig. SI4D-F $\dagger$ ). In each compound, the propionate linker showed a hydrogen bond to $\mathrm{Y}^{6 \times 51}$. Only compound 32 was still able to display hydrogen bonding to $\mathrm{K}^{6 \times 58}$ via the acetamide terminal group (Fig. SI4D-F $\dagger$ ).

Two of the analogs, 11 and 12, display antagonistic activity: the inhibition of compound 1 is $39-46 \%$ at $20 \mu \mathrm{M}$ (Table 2). These two compounds have higher similarity to other non-

Table 2 Inhibition $^{a}$ of 1 -mediated $\beta$-arrestin recruitment in $\mathrm{CHO}$ GPR132 cells upon incubation with indicated concentrations of selected $^{b}$ analogs of 1

\begin{tabular}{lllll}
\hline Compound & Inhibition $(\%)$ & SEM & Conc. $(\mu \mathrm{M})$ & $N$ \\
\hline $\mathbf{1 1}$ & 46 & 16 & 20 & 2 \\
$\mathbf{1 2}$ & 39 & 14 & 20 & 2
\end{tabular}

${ }^{a}$ The responses have been normalized to ligand buffer $(100 \%$ inhibition) and $8.5 \mu \mathrm{M}\left(\mathrm{EC}_{80}\right)$ of $\mathbf{1}\left(0 \%\right.$ inhibition). ${ }^{b}$ Compounds with more than $25 \%$ inhibition were considered as antagonists. antagonist analogs than to each other. Compound $\mathbf{1 1}$ is one of five analogs, 7-11, which have a linker that is one atom longer than in compound $\mathbf{1}$. Moreover, $\mathbf{1 1}$ is unique in that it has the largest terminal substituent, an indole, and lacks a preceding polar functionality. 12 is one of three 1-substitued anthraquinones $(\mathbf{1 2}, 16$ and 29). Compared to 16 the ring of 12 is nonaromatic and positioned on a one atom longer linker. Furthermore, varying linker lengths are seen among both agonistic and antagonistic analogs; compounds 9, 11, 12, and 18 have linkers that are between one atom longer and two atoms shorter.

Taken together, the testing of commercially available analogs has allowed for the derivation of preliminary structureactivity relationships, that although limited, can serve as a guide for further lead optimization by custom synthesis.

\section{Conclusions}

The association of GPR132 with several alternative proposed physiological ligands and functions warrants the development of tool compounds that can be used to characterize this receptor. In this work, we have disclosed the first surrogate agonist 1. The analogs tested, and the binding modes and structure-activity relationships proposed herein, will be valuable for future medicinal chemistry optimization of compound $\mathbf{1}$, as well as mutagenesis of interacting receptor residues.

\section{Acknowledgements}

M.A.S. was supported by a research scholarship from the Drug Research Academy and Novo Nordisk A/S. D.E.G. and H.B.-O. gratefully acknowledge financial support by the Carlsberg Foundation. D.E.G. and D.S.P. gratefully acknowledges financial support by the Lundbeck Foundation. Nils Nyberg is acknowledged for help with NMR spectroscopy. NMR equipment used in this work was purchased via a grant from The Lundbeck Foundation (R77-A6742). H.B.-O. gratefully acknowledges financial support from the Danish Ministry of Science, Innovation, and Higher Education.

\section{References}

1 M. N. Davies and D. R. Flower, Methods Mol. Biol., 2009, 528, 25-36.

2 S. Granier and B. Kobilka, Nat. Chem. Biol., 2012, 8, 670-673.

3 M. C. Lagerstrom and H. B. Schioth, Nat. Rev. Drug Discovery, 2008, 7, 339-357.

4 J. P. Overington, B. Al-Lazikani and A. L. Hopkins, Nat. Rev. Drug Discovery, 2006, 5, 993-996.

5 A. L. Hopkins and C. R. Groom, Nat. Rev. Drug Discovery, 2002, 1, 727-730.

6 R. Fredriksson, M. C. Lagerstrom, L. G. Lundin and H. B. Schioth, Mol. Pharmacol., 2003, 63, 1256-1272.

7 J. H. Kabarowski, K. Zhu, L. Q. Le, O. N. Witte and Y. Xu, Science, 2001, 293, 702-705.

8 O. N. Witte, J. H. Kabarowski, Y. Xu, L. Q. Le and K. Zhu, Science, 2005, 307, 206. 
9 N. Murakami, T. Yokomizo, T. Okuno and T. Shimizu, J. Biol. Chem., 2004, 279, 42484-42491.

10 H. Obinata, T. Hattori, S. Nakane, K. Tatei and T. Izumi, J. Biol. Chem., 2005, 280, 40676-40683.

11 M. Bercher, B. Hanson, C. van Staden, K. Wu, G. Y. Ng and P. H. Lee, Assay Drug Dev. Technol., 2009, 7, 133-142.

12 C. G. Radu, A. Nijagal, J. McLaughlin, L. Wang and O. N. Witte, Proc. Natl. Acad. Sci. U. S. A., 2005, 102, 1632-1637.

13 D. E. Gloriam, S. M. Foord, F. E. Blaney and S. L. Garland, J. Med. Chem., 2009, 52, 4429-4442.

14 C. Peter, M. Waibel, C. G. Radu, L. V. Yang, O. N. Witte, K. Schulze-Osthoff, S. Wesselborg and K. Lauber, J. Biol. Chem., 2008, 283, 5296-5305.

15 T. Hattori, H. Obinata, A. Ogawa, M. Kishi, K. Tatei, O. Ishikawa and T. Izumi, J. Invest. Dermatol., 2008, 128, 1123-1133.

16 B. W. Parks, A. J. Lusis and J. H. Kabarowski, Arterioscler., Thromb., Vasc. Biol., 2006, 26, 2703-2709.

17 Y. Rikitake, K. Hirata, T. Yamashita, K. Iwai, S. Kobayashi, H. Itoh, M. Ozaki, J. Ejiri, M. Shiomi, N. Inoue, S. Kawashima and M. Yokoyama, Arterioscler., Thromb., Vasc. Biol., 2002, 22, 2049-2053.

18 D. T. Bolick, A. M. Whetzel, M. Skaflen, T. L. Deem, J. Lee and C. C. Hedrick, Circ. Res., 2007, 100, 572-580.

19 D. T. Bolick, M. D. Skaflen, L. E. Johnson, S. C. Kwon, D. Howatt, A. Daugherty, K. S. Ravichandran and C. C. Hedrick, Circ. Res., 2009, 104, 318-327.

20 L. Q. Le, J. H. Kabarowski, S. Wong, K. Nguyen, S. S. Gambhir and O. N. Witte, Cancer Cell, 2002, 1, 381-391.

21 A. Gotoh and H. E. Broxmeyer, Curr. Opin. Hematol., 1997, 4, 3-11.

22 S. L. Garland and D. E. Gloriam, Curr. Top. Med. Chem., 2011, 11, 1872-1881.

23 T. Guo and D. W. Hobbs, Assay Drug Dev. Technol., 2003, 1, 579-592.

24 C. D. Duarte, E. J. Barreiro and C. A. Fraga, Mini-Rev. Med. Chem., 2007, 7, 1108-1119.

25 A. Gaulton, L. J. Bellis, A. P. Bento, J. Chambers, M. Davies, A. Hersey, Y. Light, S. McGlinchey, D. Michalovich, B. AlLazikani and J. P. Overington, Nucleic Acids Res., 2012, 40, D1100-D1107.

26 S. K. Nijssen and J. N. Kok, presented in part at the Proceedings of the 10th ACM SIGKDD International Conference on Knowledge DiscoVery and Data Mining (KDD), 2004.

27 ChemAxon, Instant JChem, 6.2.0, edn, 2014.

28 Schrödinger, Maestro, LLC, New York, NY, 9.9 edn, 2014.

29 C. G. Radu, L. V. Yang, M. Riedinger, M. Au and O. N. Witte, Proc. Natl. Acad. Sci. U. S. A., 2004, 101, 245-250.

30 D. L. Bassoni, W. J. Raab, P. L. Achacoso, C. Y. Loh and T. S. Wehrman, Methods Mol. Biol., 2012, 897, 181-203.

31 C. Southern, J. M. Cook, Z. Neetoo-Isseljee, D. L. Taylor, C. A. Kettleborough, A. Merritt, D. L. Bassoni, W. J. Raab, E. Quinn, T. S. Wehrman, A. P. Davenport, A. J. Brown, A. Green, M. J. Wigglesworth and S. Rees, J. Biomol. Screening, 2013, 18, 599-609.
32 H. Yin, A. Chu, W. Li, B. Wang, F. Shelton, F. Otero, D. G. Nguyen, J. S. Caldwell and Y. A. Chen, J. Biol. Chem., 2009, 284, 12328-12338.

33 T. P. Kenakin, A Pharmacology Primer, Third edn, 2009, pp. 149-177.

34 C. Zhang, Y. Srinivasan, D. H. Arlow, J. J. Fung, D. Palmer, Y. Zheng, H. F. Green, A. Pandey, R. O. Dror, D. E. Shaw, W. I. Weis, S. R. Coughlin and B. K. Kobilka, Nature, 2012, 492, 387-392.

35 V. Isberg, B. Vroling, R. van der Kant, K. Li, G. Vriend and D. Gloriam, Nucleic Acids Res., 2014, 42, D422-D425.

36 B. Wu, E. Y. Chien, C. D. Mol, G. Fenalti, W. Liu, V. Katritch, R. Abagyan, A. Brooun, P. Wells, F. C. Bi, D. J. Hamel, P. Kuhn, T. M. Handel, V. Cherezov and R. C. Stevens, Science, 2010, 330, 1066-1071.

37 K. Fidom, V. Isberg, A. S. Hauser, S. Mordalski, T. Lehto, A. J. Bojarski and D. E. Gloriam, Methods, 2015, 71, 104-112. 38 K. Tamura, D. Peterson, N. Peterson, G. Stecher, M. Nei and S. Kumar, Mol. Biol. Evol., 2011, 28, 2731-2739.

39 N. Eswar, D. Eramian, B. Webb, M. Y. Shen and A. Sali, Methods Mol. Biol., 2008, 426, 145-159.

40 A. S. Kolaskar and S. Sawant, Int. J. Pept. Protein Res., 1996, 47, 110-116.

41 R. A. Laskowski, M. W. Macarthur, D. S. Moss and J. M. Thornton, J. Appl. Crystallogr., 1993, 26, 283-291.

42 G. M. Sastry, M. Adzhigirey, T. Day, R. Annabhimoju and W. Sherman, J. Comput.-Aided Mol. Des., 2013, 27, 221-234.

43 T. A. Halgren, R. B. Murphy, R. A. Friesner, H. S. Beard, L. L. Frye, W. T. Pollard and J. L. Banks, J. Med. Chem., 2004, 47, 1750-1759.

44 J. C. Shelley, A. Cholleti, L. L. Frye, J. R. Greenwood, M. R. Timlin and M. Uchimaya, J. Comput.-Aided Mol. Des., 2007, 21, 681-691.

45 A. E. Cho, V. Guallar, B. J. Berne and R. Friesner, J. Comput. Chem., 2005, 26, 915-931.

46 A. D. Bochevarov, E. Harder, T. F. Hughes, J. R. Greenwood, D. A. Braden, D. M. Philipp, D. Rinaldo, M. D. Halls, J. Zhang and R. A. Friesner, Int. J. Quantum Chem., 2013, 113, 2110-2142. 47 T. A. Halgren, J. Chem. Inf. Model., 2009, 49, 377-389.

48 V. Isberg, C. de Graaf, A. Bortolato, V. Cherezov, V. Katritch, F. H. Marshall, S. Mordalski, J.-P. Pin, R. C. Stevens, G. Vriend and D. E. Gloriam, Trends Pharmacol. Sci., 2015, 36, 22-31.

49 ChemAxon, MarvinSketch, 5.12.3 edn, 2014.

50 Schrödinger, The PyMOL Molecular Graphics System, LLC, New York, NY, 1.7.4 edn.

51 Schrödinger, MacroModel, LLC, New York, NY, 10.5 edn, 2014. 52 D. Shivakumar, J. Williams, Y. Wu, W. Damm, J. Shelley and

W. Sherman, J. Chem. Theory Comput., 2010, 6, 1509-1519.

53 C. de Graaf, N. Foata, O. Engkvist and D. Rognan, Proteins, 2008, 71, 599-620.

54 A. Manglik, A. C. Kruse, T. S. Kobilka, F. S. Thian, J. M. Mathiesen, R. K. Sunahara, L. Pardo, W. I. Weis, B. K. Kobilka and S. Granier, Nature, 2012, 485, 321-326.

55 Q. Tan, Y. Zhu, J. Li, Z. Chen, G. W. Han, I. Kufareva, T. Li, L. Ma, G. Fenalti, J. Li, W. Zhang, X. Xie, H. Yang, H. Jiang, V. Cherezov, H. Liu, R. C. Stevens, Q. Zhao and B. Wu, Science, 2013, 341, 1387-1390. 